\section{Santos y beatos de la medicina en las grandes guerras del siglo $\mathrm{XX}$}

\author{
MARÍA AGUSTINA MARTINI ${ }^{1, a}$, BÁRBARA C. FINN², \\ JULIO E. BRUETMAN ${ }^{2}$, PABLO YOUNG ${ }^{1}$
}

\section{Saints in medicine during the great wars of the twentieth century}

In the political and social context of World War periods and unstoppable technological advances, health professionals in the early twentieth century tried to orientate the practice of medicine towards a modern anthropological concept close to the biomedical perspective, which defends the dignity of a person. Threatened by the risks represented by collectivism and the meanness of the prevailing repressive governments, a personal struggle for the defense of life aroused, which was socially expressed by the advent of bioethics, psychoanalytic theories and the concept that environment has an important role in people's health and welfare. And above all, the appearance of a paradoxical claim of religious ideals as support of science in times of overall crisis.

(Rev Med Chile 2016; 144: 1207-1213)

Key words: Doctors; History of Medicine; History, 20 ${ }^{\text {th }}$ Century; Warfare; World Wars; World War I; World War II.

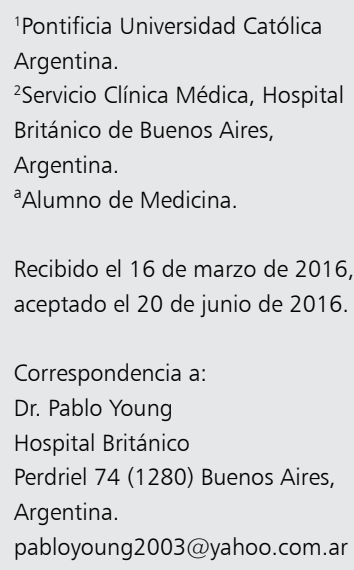

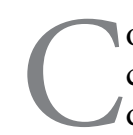
ondicionados por la temática de la persecución, la poetisa judía y Premio Nobel de literatura, Nelly Sachs, describe: “Todo comienza con el anhelo"'. Esta frase se convierte en clave para explicar el motor de los Santos y Beatos del período de guerras en el Siglo XX. La fidelidad a la propia conciencia y la experiencia del padecimiento en tiempos de conflicto, desata el impulso heroico de renunciar a su propia vida a favor del servicio de la humanidad. Recordando las palabras del filósofo alemán Theodor Adorno (1903-1969) "La esperanza está, primordialmente, en los que no hallan consuelo"?.

\section{Protagonistas significativos de la medicina solidaria mundial de 1870 a 1970}

Las biografías médicas continúan ofreciendo ventanas hacia un mundo médico más vasto ${ }^{3}$. La historia del siglo XIX y principios del XX, enfocada a las vidas de "los grandes personajes", ya no sólo trata de escribir las historias de los profesionales de la salud y sus descubrimientos, sino de comprender esos acontecimientos en un contexto general, en relación con su trascendencia universal, pero en balance con la particularidad de ese tiempo ${ }^{3}$.

Los personajes biografiados contribuyeron no sólo en la medicina, sino en la religión, la política, la literatura y la asistencia social. Estos actuaron en un período muy traumático de la historia, y fueron reconocidos por la Iglesia Católica como seres excepcionales en su fe y en su pasión por cuidado de los enfermos a su cargo. Protagonistas de la concepción de medicina solidaria, por orden cronológico, son: Beato Ladislao Batthyány-Strattmann (1870-1931); Santo Giuseppe Moscati (1880-1927); Santa María Bertila Boscardín (1888-1922); Santa Edith Stein (1891-1942) y Santa Gianna Bereta Mola (1922-1962) y en ese orden se expondrán.

\section{Beato Ladislao Batthyány-Strattmann}

Nació el 28 de octubre de 1870 en Dunakiliti, Hungría (Figura 1). En 1896 comenzó los estudios 
de medicina y en 1898 se casó con la condesa María Teresa Coreth, con quien tuvo trece hijos. En 1902 fundó un hospital privado en Kittsee con veinticinco camas. Dijo: "seré médico y curaré gratuitamente a los enfermos pobres". Con este objetivo, que más adelante se transformaría en su insignia vocacional, creció profesionalmente. Durante la primera guerra mundial, ante el aumento de la demanda, el hospital fue ampliado a 120 camas. Asimismo, al heredar el castillo de Körmend en Hungría, se trasladó con su familia y creó en una parte del mismo otro hospital. A cambio de la terapia y los cuidados les pedía a sus pacientes que rezaran por él. Eran tantos pacientes provenientes de todo el país, que obligaron a los ferrocarriles húngaros a preparar un tren especial que llegara hasta el hospital. Antes de las operaciones invocaba, conjuntamente con los enfermos, la bendición de Dios. Se sintió instrumento en las manos de Dios. Falleció el 22 de enero de 1931 en Viena ${ }^{4}$.

En su beatificación el 23 de marzo de 2003, el Papa Juan Pablo II declaró: "Fue padre de familia y médico. Su mayor interés no eran los bienes materiales; en su vida no buscó el éxito. Eso fue lo que enseñó y vivió en su familia, convirtiéndose así en el mejor testigo de la fe para sus hijos. Él jamás antepuso las riquezas de la tierra al verdadero bien, que está en los cielos"

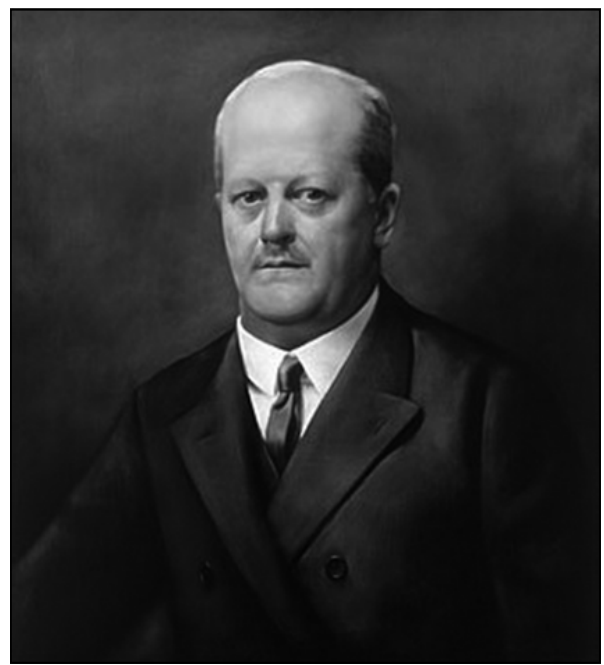

Figura 1. László Batthyány-Strattman. En: http://www. patertv.com/upself2.0/riflessioni/immagini/stratt-man.gif; consultado el 21/12/15.

\section{Santo Giuseppe Moscati}

José Moscati nació en Benevento, Italia, el 25 de julio de 1880 (Figura 2). A los 4 años su familia se trasladó a Nápoles, donde vivió hasta sus últimos días. Se recibió el 4 de agosto de 1903 en la Universidad de Nápoles con la tesis "ureogénesis hepática”. Durante estos años la ciudad de Nápoles fue sacudida por dos grandes eventos naturales. Por un lado la erupción del Vesuvio el 8 de abril de 1906, y por otra parte, al ser Nápoles una ciudad portuaria, favoreció la difusión del cólera en 1911. A pesar del aumento de sus tareas en el Hospital, Moscati visitó a los enfermos que no podían trasladarse en sus respectivos hogares.

En 1911 ganó el concurso de Auxiliar numerario en los Hospitales Reunidos. Se trató de un concurso de suma importancia que no se realizaba desde 1880. El Profesor Antonio Cardarelli (18311927), quien formó parte de los examinadores, se quedó admirado por la preparación de Moscati y "dijo que en 60 años de enseñanza nunca le había tocado un joven tan preparado" 6 .

Desde entonces grupos de estudiantes y médicos jóvenes lo seguían de una cama a la otra, para aprender el secreto de su habilidad. Su filosofía de vida puede verse representada en una carta que Moscati le escribió al Dr. Francesco Pentimalli (1885-1958): “(...) Creo que todos los jóvenes

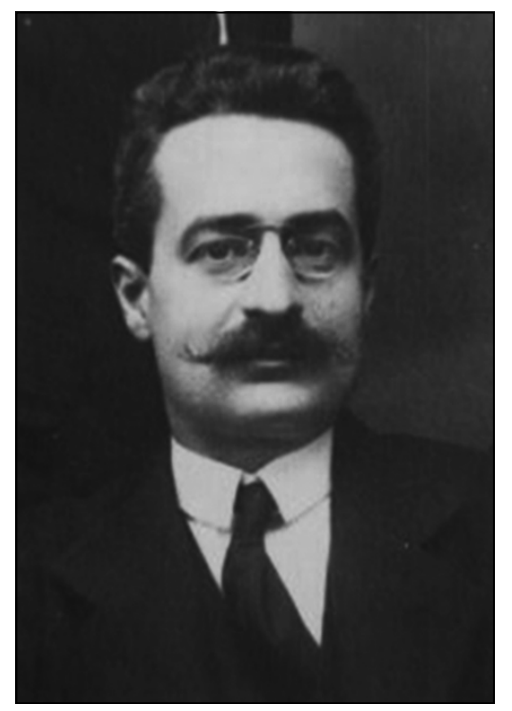

Figura 2. José Moscati. En: http://es.catholic.net/op/articu-los/34777/jos-moscati-santo.html; consultado el 21/12/15. 
que han emprendido el camino de la noble medicina, tienen derecho a perfeccionarse mediante la lectura de un libro que no ha sido impreso con caracteres negros sobre el papel, sino que tiene como soporte las camas del hospital y las salas de laboratorio, y como contenido la carne doliente de los hombres y el material científico. Un libro para leer con infinito amor y gran sacrificio hacia el prójimo (...)"6.

Las publicaciones de Moscati desde 1903, año de su licenciatura, a 1916, fueron veintisiete. Todo esto llevó a que fuera designado en 1917 para la Dirección de las investigaciones científicas en el Instituto de Química Fisiológica, pero renunció a la cátedra, ya que al estar su país en guerra, optó por dedicarse tiempo completo al trabajo hospitalario.

La primera guerra mundial llegó a Italia en 1915 y el llamamiento empezó a diezmar las familias. Como su hermano Eugenio partió al frente ese mismo año, Moscati solicitó incorporarse como voluntario, sin que se lo concedieran. Las autoridades militares le encomendaron el cuidado de los heridos que iban llegando al Hospital de los Incurables, que fue militarizado.

La fama de Moscati como maestro y médico fue creciendo en todo Nápoles. Se hablaba de la didáctica de sus clases, sus habilidades diagnósticas y de su generoso trabajo con los enfermos. El 14 de octubre de 1922 el Ministro de la Pública Instrucción le confirió la libre docencia en Clínica médica y tres días después escribe: “(...) Ama la verdad, muéstrate cómo eres, sin fingimientos, sin miedos y sin recelos. Y si la verdad te cuesta la persecución, tú acéptala, y si te cuesta el tormento, tú sopórtalo. Y si por la verdad tuvieras que sacrificarte a ti mismo y a tu propia vida, sé fuerte en el sacrificio (...)"'.

A diferencia de sus colegas, y a pesar de su renombre, optó por una vida de pobreza y sencillez material. Así vivió su fe cristiana, participó de manera diaria de la Santa Misa y lo que recibió como honorario, lo dirigió a los pobres. Así lo describe: "El haber salvado un alma será para mí el mejor honorario que puedo apetecer" .

Moscati en cada paciente del hospital sostiene y enseña el amor a la ciencia, en el servicio al dolor: “(...) Bienaventurados nosotros los médicos, incapaces muchas veces de curar una enfermedad. Dichosos si nos acordamos de que, además de los cuerpos, tenemos ante nosotros almas inmortales, ante las cuales nos urge el precepto evangélico de amarlas como a nosotros mismos. Los enfermos son la imagen de Jesucristo (...)" .

Falleció el 12 de abril de 1927. Fue canonizado por el Papa Juan Pablo II, el 16 de octubre de 1987, quien declaró: “(...) Por naturaleza y vocación, Moscati fue ante todo y sobre todo médico, responder a las necesidades de los hombres y a sus sufrimientos fue para él una necesidad imperiosa e imprescindible. El dolor del que está enfermo llegaba a él como el grito de un hermano a quien otro hermano, el médico, debía acudir con al ardor del amor. El móvil de su actividad como médico no fue, pues, solamente el deber profesional, sino la conciencia de haber sido puesto por Dios en el mundo para obrar según sus planes y para llevar, con amor, el alivio que la ciencia médica ofrece, mitigando el dolor y haciendo recobrar la salud. Por lo tanto, se anticipó y fue protagonista de esa humanización de la medicina, que hoy se siente como condición necesaria para una renovada atención y asistencia al que sufre"g.

\section{Santa María Bertila Boscardín}

Nació el 6 de octubre de 1888 en Vicenza, Italia (Figura 3). A los 16 años ingresó a la casa vicentina de las Maestras de Santa Dorotea, donde hizo el

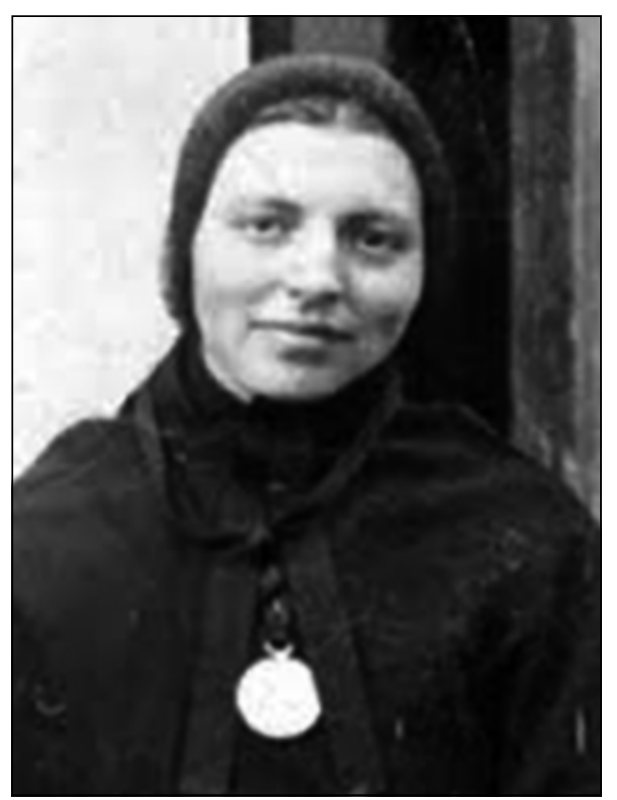

Figura 3. María Bertila Boscardín. En: http://www.senhoradorosario.org/2012/10/20-de-outubro-santa-maria-bertilla. html; consultado el 21/12/15. 
noviciado y sus primeros votos en 1905. La congregación prestaba servicio en el hospital, por lo que en 1907 se trasladó a Treviso para servir a los niños internados en el pabellón de difteria. Luego de dos años allí trabajó también en los pabellones de tuberculosis, oncología, salud mental, ancianos y el de los militares ${ }^{10}$.

Se graduó de enfermera para poder ser más útil a los enfermos. En su diario escribió: “(...) Quiero ser la servidora de todos, porque estoy convencida que así debe ser; quiero trabajar, sufrir, y dejar toda la satisfacción a los demás (...). Tengo que considerarme la última de todas, por tanto contenta de ocupar el último lugar, indiferente a todo, tanto a los reproches como a las alabanzas, y hasta preferir lo primero; siempre condescendiente con las opiniones ajenas; no excusarme nunca, aunque me parezca tener razón; nunca hablar de mí misma; los oficios más humildes sean siempre los míos, porque así obtengo méritos (...)"10.

En 1910, a la edad de 22 años, fue operada de un tumor. Y cuando estalló la guerra en 1915, estuvo asistiendo un destacamento de soldados heridos. Vivió constantemente en oración y esto explicó porque amó tanto el silencio y el recogimiento: "Cuando me callo rezo bien y estoy bien".

La Primera Guerra Mundial hizo del hospital de Treviso, no muy distante del frente de combate, uno de los puntos de concentración de militares $\mathrm{y}$ civiles heridos.

A causa de su enfermedad murió a los 34 años de edad, el 20 de octubre de 1922. Un médico del Hospital donde trabajó, dijo de ella: "Era un alma elegida y de una bondad heroica, un ángel consolador del sufrimiento humano"11. Fue beatificada en 1952 por Pío XII, que declaró: "Nada de éxtasis, nada de milagros en vida, sino una unión con Dios cada vez más profunda en el silencio, en el trabajo, en la oración, en la obediencia. De esa unión venía la exquisita caridad que ella demostraba a los pobres, a los enfermos, a los médicos, a los superiores, a todos". Y años más tarde, fue canonizada por Juan XXIII el 11 de mayo de $1961^{12}$.

\section{Santa Edith Stein}

Hija de una familia judía, Edith Stein nació el 12 de octubre de 1891 en Breslau (Figura 4), ciudad que en aquel tiempo perteneció a Alemania (hoy Wrocław, Polonia). Fue considerada una estudiante brillante, y durante estos años entró en contacto con el pensamiento de Edmund Hus- serl (1859-1938). Este generó en ella un interés profundo por la fenomenología, lo que la llevó a estudiar filosofía en la Universidad de Göttingen, donde Husserl era profesor. Sin embargo, sólo el fenomenólogo Max Scheler (1874-1928), quien había retornado a la fe católica, y defendía ideas distintas a Husserl, consiguió despertar la necesidad religiosa de Edith, a pesar de reconocerse atea. Escuchando a Scheler, se le derrumbaban las barreras de los prejuicios racionales. Ella misma dice en su diario: "El mundo de la fe se me abrió de improviso delante" ${ }^{13}$.

Por otra parte, ya en sus años de estudiante manifestó gran sensibilidad por los derechos de la mujer, por los que trabajó activamente y se dedicó a dar clases de filosofía a mujeres trabajadoras ${ }^{14}$.

Cuando comenzó la primera guerra mundial, en 1914, se sintió espiritualmente atraída por la idea de oponerse al odio con un servicio de amor. Realizó estudios de enfermería y se hizo voluntaria de la Cruz Roja en un hospital militar, situado en una pequeña ciudad de Moravia. Volvió a la filosofía con una nueva actitud: "¡No la ciencia, sino la dedicación a la vida tiene la última palabra!"15.

En 1916 siguió a Husserl como asistente en la Universidad de Friburgo, donde se licenció de filósofa con su tesis titulada "El problema de la

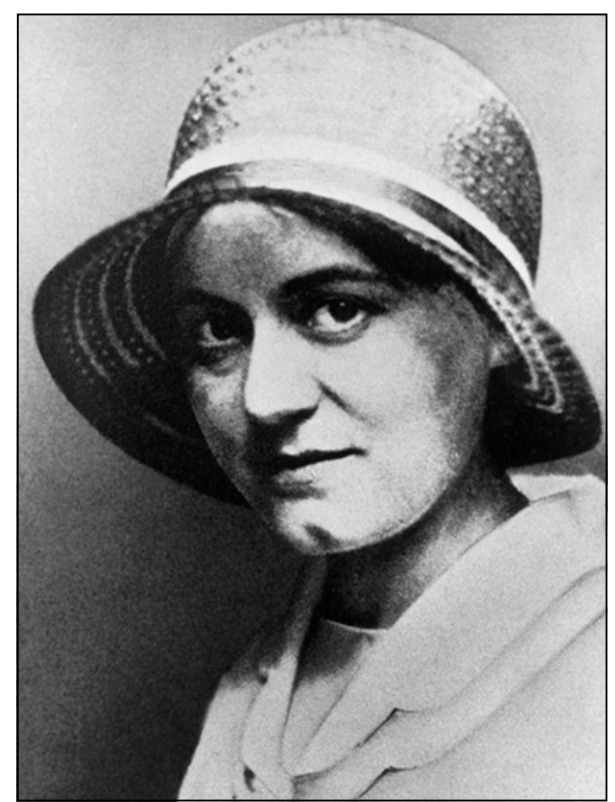

Figura 4. Santa Edith Stein. En: http://centreedithstein.com; consultado el 21/12/15. 
empatía”. El año después consiguió el doctorado en la misma universidad. Dejó su trabajo como asistente de Husserl, y decidió dedicarse a la enseñanza en el Instituto de las Dominicas de Spira.

Confrontó la corriente filosófica en la que se había formado, la fenomenología, con la filosofía cristiana de Santo Tomás de Aquino, en la que siguió profundizando. Resultado de esta investigación fue el estudio que dedicó a su antiguo maestro Husserl en 1929: "La fenomenología de Husserl y la filosofía de Santo Tomás".

Consideró importante que la Iglesia colabore con el movimiento femenino de liberación de la mujer, por lo que realizó entre 1928 y 1938 conferencias sobre la mujer y su significado en la sociedad, en diversos países de Europa.

En 1932, dejó Spira y entró como profesora de filosofía en la Academia pedagógica de Münster. Permaneció solamente un año debido a la llegada al poder de Hitler quien comenzó la promulgación de las leyes de discriminación racial, y tuvo que abandonar la enseñanza.

A los 42 años, en el año 1933, ingresó en el Carmelo de Colonia. Se hizo novicia con el nombre de Sor Teresa Benita de la Cruz. Entre tanto, completó su obra "Ser finito y Ser eterno". En 1938 hizo los votos de profesión religiosa carmelita. Pero ese mismo año tuvo que dejar Colonia y se refugió en Holanda, en el Carmelo de Echt ${ }^{13}$.

En 1941 inició una nueva obra sobre la teología mística de San Juan de la Cruz. La tituló Scientia Crucis. La obra quedó incompleta ya que los nazis la deportaron al campo de concentración de Amersfort, y de ahí a Auschwitz. “¡Vamos! -dijo mientras salía a su hermana Rose, que vivía en la hospedería del monasterio y que fue capturada junto a ella- ¡Vamos a morir por nuestro pueblo!”. Y así murió en las cámaras de gas de Auschwitz el 9 de agosto de $1942^{14}$.

Fue beatificada por Juan Pablo II en Colonia, el 1 de mayo de 1987. Y el 11 de octubre de 1998 fue proclamada Santa por el mismo pontífice. Como dirá el Papa Juan Pablo II: "Ella misma será testimonio de esta feminidad socialmente operativa, haciéndose apreciar como investigadora, conferenciante, profesora. Fue estimada como mujer de pensamiento, capaz de utilizar con sabio discernimiento las aportaciones de la filosofía contemporánea para buscar la «plena verdad de las cosas» en el continuo esfuerzo de conjugar las exigencias de la razón y las de la fe"15.

\section{Gianna Beretta Molla}

Nació en Magenta, Italia, el 4 de octubre de 1922, en el seno de una familia católica (Figura 5). En 1952 se especializó en Pediatría en la Universidad de Milán. En la práctica de la medicina, prestó una atención particular a las madres, a los niños, a los ancianos y a los pobres ${ }^{16}$.

Su trabajo profesional, que consideró como una "misión", no le impidió dedicarse a la Acción católica, intensificando su apostolado entre las jóvenes. Durante este tiempo conoció al ingeniero Pietro Molla con quien se casó. $\mathrm{Al}$ año siguiente dio a luz a su primer hijo, Pierluigi. Luego, en 1957, Mariolina y en 1959 a Laura ${ }^{16}$.

Armonizó, con simplicidad y equilibrio, los deberes de madre, de esposa, de médico y la alegría de vivir. En septiembre de 1961, al cumplirse el segundo mes de un embarazo le diagnosticaron un fibroma en el útero. Su marido manifestó en testimonio que: "Le habían aconsejado una intervención quirúrgica. Esto le habría salvado la vida con toda seguridad. El aborto terapéutico y la extirpación del fibroma, le habrían permitido más adelante tener otros niños (...) Gianna eligió la solución más arriesgada para ella". Algunos días antes del parto expreso: "Si hay que decidir

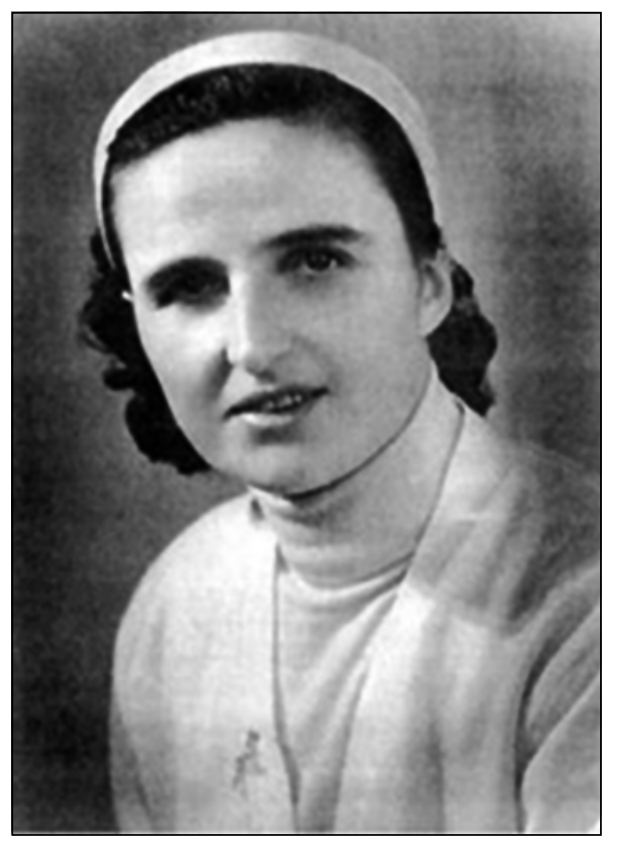

Figura 5. Gianna Beretta Mola. En: http://www.giannaberetta-molla.org; consultado el 21/12/15. 
entre mi vida y la del niño, no dudéis; elegid -lo exijo- la suya. Salvadlo". Gianna fue inspirada por la vida de la Santa Mártir María Goretti y al respecto declaró: "Ella dijo que la vida es hermosa cuando es dedicada a grandes ideales, y para ser capaz de alcanzar estos ideales, uno debe saber cómo morir" 16 .

El 21 de abril de 1962 da a luz a Gianna Emanuela y días más tarde, el 28 de abril, a los 39 años murió ${ }^{27}$. Pablo VI definió con la frase "Meditada inmolación" el gesto de la beata Gianna. Fue canonizada por Juan Pablo II el 16 de mayo de 2004, quien dijo: "Esta santa madre de familia se mantuvo heroicamente fiel al compromiso asumido el día de su matrimonio. El sacrificio extremo que coronó su vida testimonia que sólo se realiza a sí mismo quien tiene la valentía de entregarse totalmente a Dios y a los hermanos"17.

\section{Conclusión}

En cada uno de los anteriormente citados surge como valor, el uso de la libertad. Los seres humanos somos por definición seres sociales y estamos constantemente expuestos a las presiones y condicionamientos tanto biológicos como culturales. Pero el ser humano en su esencia ha demostrado su libertad, esta libertad estará siempre presente en el pensamiento de Maritain: "El acto libre, además de ser el acto de la persona como tal, es la revelación de la persona a sí misma; y tal vez ese acto personal y esa revelación sean idéntica cosa"18.

La libertad revela al hombre su propia ontología, su dignidad, su ser persona. Desde Santo Tomás que con maestría revela "Hay entes que obran sin juicio previo alguno; por ejemplo, una piedra que cae y cuantos entes carecen de conocimiento. Otros obran con un juicio previo, pero no libre; así los animales. La oveja que ve venir al lobo, juzga que debe huir de él; pero con un juicio natural y no libre, puesto que no juzga por comparación, sino por instinto natural. De igual manera, son todos los juicios de los animales. El hombre, en cambio, obra con juicio, puesto que por su facultad cognoscitiva juzga sobre lo que debe evitar o procurarse; y como este juicio no proviene del instinto natural ante un caso práctico concreto, sino de una comparación hecha por la razón, síguese que obra con un juicio libre, pudiendo decidirse por distintas cosas"19.
De Santo Tomás surge que la libertad o libre albedrío es el poder, radicado en la razón y más inmediatamente en la voluntad, de hacer o de no hacer, cada hombre ejerce el dominio de sus obras, dispone de sí mismo, se auto posee por su voluntad o se auto determina.

El acto propio que deriva de la libertad es la capacidad de elegir, por ella, tiene la posibilidad de hacer lo adecuado o no hacerlo.

En su libro "El hombre en busca de sentido", Viktor Frankl describe que: "Al hombre se le puede arrebatar todo, salvo una cosa: la última de las libertades humanas -la elección de la actitud personal ante un conjunto de circunstancias para decidir su propio camino-" 20 . Y es esta libertad espiritual lo que hace que la vida tenga sentido y propósito. Al declarar que el hombre es una criatura responsable y que debe aprehender el sentido potencial de su vida, quiere subrayar que este verdadero sentido debe encontrarse en el mundo y no dentro de su propia psique, como si se tratara de un sistema cerrado. Sin importar las ciertas condiciones biológicas, psicológicas y sociales que lo tengan sometido, el ser humano tiene la libertad de dejarse determinar por estas o no. Es por ello que la vida y obra de estos profesionales de la salud, desarrollada en el contexto de las Guerras Mundiales, son una secuencia de hechos encadenados en un testimonio incuestionable del poder desafiante del espíritu humano.

\section{Referencias}

1. Biografías y Vidas. Nelly Sachs. Extraído de http://www. biografiasyvidas.com/biografia/s/sachs_nelly.htm (consultado el 10 de octubre de 2015).

2. Adorno TW. Mínima Moralia: Reflexiones desde la vida dañada. Frankfurt: Editorial Suhrkamp Verlag; 1951. p. 50-60.

3. Robles-Valencia R. Diccionario de Biografía Médica. Bol Mex His Fil Med 2008; 33: 29-33.

4. Biografía Beato Ladislao Batthyány-Strattmann. Extraído de www.vatican.va (consultado el 12 de diciembre de 2015).

5. Beatificación de 5 siervos de Dios. Homilía del Santo Padre Juan Pablo II. Domingo 23 de marzo de 2003. Extraído de www.aciprensa.com (recuperado el 20 de diciembre de 2015).

6. Quagliariello G. Giuseppe Moscati. Medicus 1948; 41: 12-6.

7. Ponti G, Tomasi A. Giuseppe Moscati (1880-1927): a 
holistic approach to medicine. J Med Biogr 2013; 22: 80-2.

8. Biografía Giuseppe Moscati. Extraído de www.moscati. com (consultado el 14 de enero de 2016).

9. Juan Pablo II. Homilía en la Ceremonia de Canonización del Doctor José Moscati, 16 de octubre de 1987. Extraído de www.aciprensa.com (consultado el 14 de enero de 2016).

10. Maddalena PGSM. Diario spirituale della Beata Bertilla Boscardin. Vicenza: 1952. p. 2-36.

11. Federici E. Santa María Bertilla Boscardin. Vicenza: 1961. p. 11-24.

12. Turetta V. La azucena de los béricos: Santa María Bertilla Boscardín. Hermanas Maestras de Santa Dorotea, Hijas de los sagrados Corazones. Treviso: 1974. p. 1-5.

13. García Rojo E. Una mujer ante la verdad. Aproximación a la filosofía de Edith Stein. Madrid: Editorial Espiritualidad; 2002. p. 112-163.

14. Ghini E. Edith Stein: Ebrea, filosofa, carmelitana, martire.
Roma: Editorial Osservatore Romano; 1998.

15. Vila Griera MP. Edith Stein, una mujer intelectual y Santa. (Escrito redactado con motivo de la canonización de Edith Stein, Vaticano, 11 de octubre de 1998) Extraído de www.aciprensa.com (consultado el 16 de enero de 2016).

16. Betancourt D. Santa Gianna Beretta Molla: esposa, madre, médico, mártir. Buenos Aires: Editorial Tierra Nueva; 2011. p. 27-42.

17. Biografía Gianna Beretta Molla. Extraído de www.vatican.va (consultado el 24 de enero de 2016).

18. McCurry MK, Revell SM, Roy SC. Knowledge for the good of the individual and society: linking philosophy, disciplinary goals, theory, and practice. Nurs Philos 2010; 11: 42-52.

19. Torralba F. La esencia del sufrimiento. An Sist Sanit Navar 2007; 30: 23-37.

20. Frankl VE. Man's Search for Meaning. Alemania.1946. p. 85-106. 